$\xi=-1$

\title{
Feasibility Study of Fiber to the Home Networks for Optical Fiber Loss and Attenuation
}

\author{
Edy Budiman ${ }^{1 *}$, Haviluddin², Masna Wati ${ }^{3}$, Medi Taruk $^{4}$, Hario Jati Setyadi ${ }^{5}$, Herman Santoso Pakpahan ${ }^{6}$ \\ ${ }^{1}$ Universitas Mulawarman, Samarinda, Indonesia \\ *Corresponding author E-mail: edy.budiman@fkti.unmul.ac.id
}

\begin{abstract}
The utilization of optical fiber cable as a data transmission medium has provided various benefits and advantages in terms of data transfer and economically because it can reduce the use of many copper cables. The purpose of this study was to evaluate the feasibility of Fiber To The Home (FFTH) networks by measuring and analyzing power losses caused by attenuation along the fiber optic cable. Measuring tools for attenuation use JDSU MTS- 8000 while the power measurement uses Optical Power Meter. Feasibility specifications refer to ITU-T G.984. recommendations. The analysis results show that of the 110 customers observed, the average value of Link Power Budget is $20.58 \mathrm{~dB}$, with an average power margin of $5.57 \mathrm{dBm}$. If comparing the results of the ITU-T G.984 recommendation, it stated that was accepted, still in accordance with the rules specifications. Feasibility studies of FTTH networks on the issue of power loss and attenuation are needed in an effort to maintain the quality of service to customers. It also has a relationship with planning and developing system installations in the future.
\end{abstract}

Keywords: Optical; Fiber; Attenuation; FTTH; Networks.

\section{Introduction}

The need for communication services with fast information transmission, better signal quality, and safer security factors make technology must be developed and updated. To achieve highspeed information transmission, a large bandwidth is needed. Internet service providers (ISPs) are constantly pursuing requests for higher bandwidth and data throughput. Over time ISPs, have migrated their services from UTP networks to Optical networks. ISP is the power to accommodate increased bandwidth requirements because new services used on a global scale tend to gradually require more bandwidth [1].

The use of Fiber to The Home (FTTH) networks that use Fiber Optics as a transmission medium can meet the needs of residential customers to find a faster network connection for broadband services [2]. This thirst for speed has surpassed even the latest predictions, driven in part by downloading or channeling more, and more video content over the Web, the success of unexpected high definition television, and the increasingly popular exchange of photography, video and audio content. New uses that support greater bandwidth occur on an ongoing basis and many service providers plan networks capable of $50 \mathrm{Mb} / \mathrm{s}, 100 \mathrm{Mb} / \mathrm{s}$, or higher, per customer [2]. With technology that continues to grow and end users who demand faster internet speeds, optical fiber technology is the best choice [3].

Gigabyte Passive Optical Networks (GPON) is a network technology, which relies on optical cables to convey information. With one optical fiber capable of supporting multiple users because the use of passive optical splitters makes GPON have the advantage of reducing equipment, meeting areas with high density and supporting triple play services; voice, date and IP video with the level of public demand [3]. GPON has been seen as an important part of many FTTH strategies. Several studies have been conducted on the quality issues of FTTH networks using GPON technology, such as [4], [5]. In Indonesia, the design and development of FTTH must meet recommendations [6-8] and in accordance with the standards by ITU-T. G.984.x. Along with the increase and growth use of fiber optic cable as a data transmission medium, it also often occurs information loss factors caused by losses that occur along the fiber optic cable, one of these losses is the power lost due to attenuation that produces power changes from an optical transmitter to reach the optical receiver.

This study was motivated by the frequent occurrence of disruption in one STO at the study site. Several times in each month there is a report of service interruptions and does not reach the customer [9-14], where the results of measurements in the field with an OTDR (Optical Time Domain Reflectometer) gauge show the results of the link power budget above $28 \mathrm{~dB}$. This is beyond the standard for the Link Power Budget, this is what triggers the arrival of optical signals to Optical Network Terminal (ONT) devices in the customer's home. If the total attenuation is not in accordance with the standard, the guarantee of the quality of services provided by the ISP will not be in accordance with the customer's expectations.

The issue of optical power attenuation and also has a relationship with the planning of the installation of fiber optic cable communication systems. When the system experiences interruption along fiber optic cable, in this case, it occurs in one of the Internet Service Providers (ISPs) in Indonesia, from attenuation and power data that occurs at the ISP, then conducts research to analyze the performance of fiber optic communication systems caused by attenuation and strength along fiber optic cable.

The purpose of this study was to evaluate the feasibility of Fiber To The Home (FFTH) networks by measuring and analyzing power losses caused by attenuation along the fiber optic cable. Measuring tools for attenuation use JDSU MTS-8000 while the power measurement uses Optical Power Meter. Feasibility specifi- 
cations refer to ITU-T G.984.2 recommendations. Feasibility studies of FTTH networks on the issue of power loss and attenuation are needed in an effort to maintain the quality of service to customers. It also has a relationship with planning and developing system installations in the future.

\section{Materials and Methods}

\subsection{Design Network Architecture and Measuring Tools}

Fig. 1, the network architectural design of Link Power Budget measurements from Optical Line Terminal (OLT) to Optical Network Terminal/Unit (ONT/ONU) terminals subscribers.

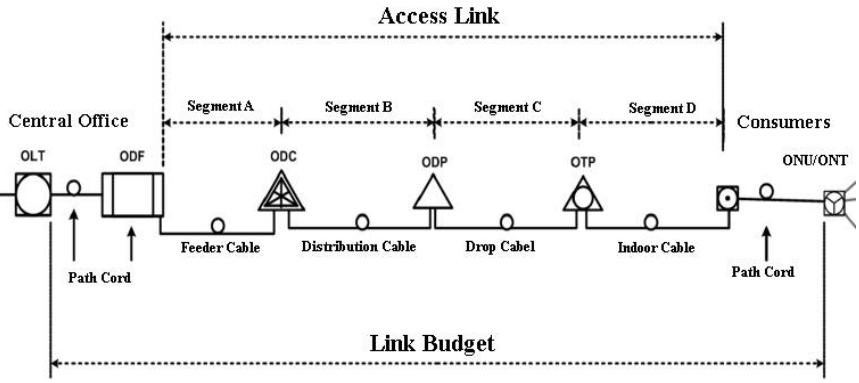

Fig. 1: The network architectural design of Link Power Budget measurements

In general, The FTTH networks divided into 4 segments of cables in addition to active traps like OLT and ONU/ONT, i.e.

1. Segment A: Feeder cable

2. Segment B: Distribution cable

3. Segment C: Drop cable

4. Segment D: Home wiring (Indoor cable).

Measuring instrument for attenuation using JDSU MTS-8000 while measuring power using Optical Power Meter in Fig. 2.

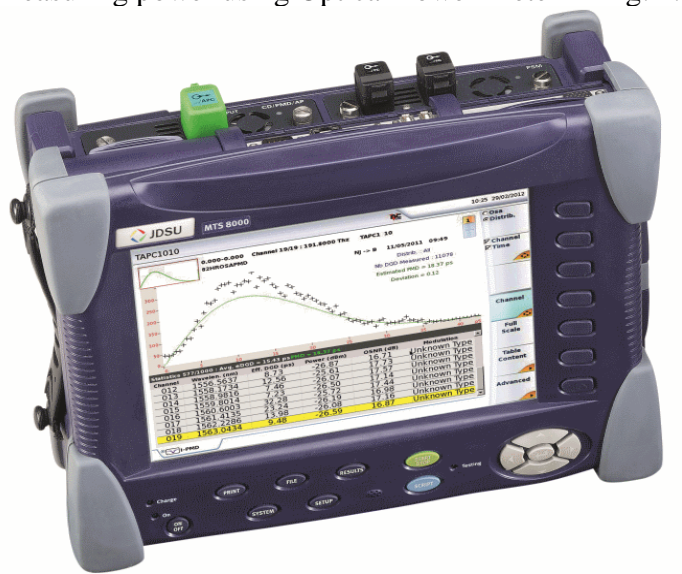

Fig. 2: JDSU MTS-8000

One function of this tool is to measure attenuation due to events that occur along fiber optic cables, this measuring instrument works based on the time domain, which is the reflected light captured when the laser is fired into fiber optic cables to identify the core characteristics of optical fibre characterization. In measuring fibre attenuation, the point-to-point relationship measures from end to original to end and end the original. The items that can be measured in this tool are the attenuation coefficient, reflection, and error point, based on the distance function. JDSU MTS-8000 is a highly integrated test platform for all phases of the fiber network life cycle, it provides field service technicians with the highest level of performance and upgradeability. More than 40 application modules are supported for multimode and single mode. Very lightweight compact platform. Generates performance-proof reports. Perform full fiber characterization measurements. JDSU MTS-8000 Scalable Optical Test Platform without additional tools and easy to use without the need for training when used.
To measure the power level using 2 units. The first unit that functions as a transient is to use an optical Light Source and the second unit functions as a receiver using an Optical Power Meter. A typical optical power meter consists of a calibrated sensor, measuring amplifier and display. This sensor consists mainly of photodiodes selected for the right range of wavelengths and power levels. On the display unit, optical power is measured and the wavelength is displayed. Calibrated electric meters using a calibration standard can be tracked like the NIST standard. Optical power meters are combined with different test functions such as Optical Light Source (OLS), When combined with a light source, the instrument is usually called an Optical Loss Test Set.

\subsection{Data Collection Methods}

Data collection techniques use field measurement methods. Data is collected from the Optical Line Terminal of the total user population. The population of the customer's internet number is currently taken from the user node. The number of samples is shown in Table 1.

Table 1: Number of consumers based on Optical Distribution Network (ODN)

\begin{tabular}{|c|c|}
\hline Optical Distribution Network (ODN) & Number of Customers \\
\hline ODC-FAA & 9 \\
\hline ODC-FAB & 26 \\
\hline ODC-FB & 9 \\
\hline ODC-FC & 7 \\
\hline ODP-FE & 6 \\
\hline ODC-FF & 13 \\
\hline ODP-FG & 12 \\
\hline ODC-FJ & 2 \\
\hline ODC-FK & 4 \\
\hline ODC-FL & 2 \\
\hline ODC-FM & 38 \\
\hline ODC-FT & 11 \\
\hline ODC-FU & 4 \\
\hline ODC-FV & 3 \\
\hline ODC-FW & 3 \\
\hline ODC-FX & 4 \\
\hline Total & 153 \\
\hline
\end{tabular}

The customer data is collected and analyzed to ensure that the internet is equipped with registration numbers and internet numbers are installed correctly in the customer's home. In the Table 1, there is 16 distribution of optical networks for networks service to customers which are Outdoor devices in fiber optic access networks. Optical Distribution Cabinet (ODC) functions as a place to install a single-mode optical network connection, which can contain connectors, splicing, or splitters and is equipped with fiber management space with a certain capacity in GPON, for telecommunication relations. ODC functions as a termination place between feeder cables and distribution cables. In ODC there are central or splitters which are divided into Optical Distribution Point (ODP) or service distribution boxes to customers, their function as the termination point of the optical drop cable towards the customer and the distribution point, the distribution cable becomes several optical drop lines using a splitter.

\section{Network Quality Parameters for FTTH}

The link power budget is calculated as a requirement for the link that we design the power beyond the threshold of the required power. To calculate the link power budget can be calculated by the equation [15-16]:

$$
\alpha_{\text {tot }}=\text { L. } \alpha_{\text {fiber }}+\text { Nc. } \alpha_{c}+\text { Ns. } \alpha_{s}+\text { Sp }
$$

The equation for the power margin calculation is: 
$\mathrm{M}=(\mathrm{Pt}-\mathrm{Pr})-\alpha_{\text {total }}-\mathrm{SM}$

Where:

Pt : Output power $(\mathrm{dBm})$

$\mathrm{Pr} \quad$ : Maximum power sensitivity $(\mathrm{dBm})$

SM : Safety margin

$\alpha$ tot : Total attenuation $(\mathrm{dB})$

$\mathrm{L} \quad$ : Fiber Length $(\mathrm{Km})$

$\alpha \mathrm{c} \quad$ : Connector attenuation

$\alpha \mathrm{s} \quad:$ Attenuation of the connection

fiber $\alpha \quad$ : fiber attenuation $(\mathrm{dB} / \mathrm{Km})$

Ns : Number of connections

Nc : Number of connectors

Sp : attenuation Splitter $(\mathrm{dB})$

Analysis of measurement data that has been obtained will be adjusted with the recommendations of ITU [6-8]. Table 2 presents the recommendations ITU for specification of GPON.

Table 2: Specification of GPON recommendation ITU-T. G.984.2 [6-8]

\begin{tabular}{|l|l|}
\hline \multicolumn{1}{|c|}{ Items } & \multicolumn{1}{c|}{ Target Description } \\
\hline Service performance and QOS & $\begin{array}{l}\text { Full Services (19/100 Base-T, } \\
\text { Voice, Leased lines) }\end{array}$ \\
\hline bit rate of the OLT to ONU signal & $\begin{array}{l}\text { Down 1244.16, or 2488.32 Mbit/s. } \\
\text { Up 155.52, 622.08, 1244.16, or } \\
2488.32 \mathrm{Mbit} / \mathrm{s}\end{array}$ \\
\hline $\begin{array}{l}\text { Maximum Physical distance (OLT } \\
\text { to ONT) }\end{array}$ & Max 20 km and Max 10 km \\
\hline Operating Wavelengths & $\begin{array}{l}\text { Downstream: } 1480-1500 \mathrm{~nm} \\
\text { Upstream: } 1260-1360 \mathrm{~nm}\end{array}$ \\
\hline Transmission rate (Mbps) & $\begin{array}{l}\text { Down: } 1244,2488 \\
\text { Up: } 155,622,1244,2488\end{array}$ \\
\hline Max. Number of splitters per ONT & 128 \\
\hline Attenuation range & $\begin{array}{l}\text { Class A: 5-20 dB } \\
\text { Class B: } 10-25 \mathrm{~dB} \\
\text { Class C: } 15-30 \mathrm{~dB}\end{array}$ \\
\hline Split ration & Up to 64 \\
\hline
\end{tabular}

Research on GPON performance analysis from Link Power Budget and QoS Trafficking was previously carried out by A Ubaidillah, et al. [17]. From the results of his observations indicate that the GPON link power budget system is in good condition. Meet the ITU-T G984 Class B standard. Whereas the traffic performance observations show that the customer network resource utility in the observed area is not optimal. M. El-Ghazali Hamza and K. Bashir Bugaje [18], this study proposes a simulation of the standard fiber-To-The-Home (FTTH) GPON to provide reliable connections for 64 customers, using Optisystem over a distance of $50 \mathrm{~km}$. Medi Taruk. Et al. Comparison of TCP variants in Long Term Evolution (LTE) [19], Hammadi, A. et al. [20], Have shown a study to analyze worse levels of commitment for different separate ratios per PON with respect to different network loads. Has demonstrated and justified the limitations of the specifications of the transmission distance from PON links to not exceeding $20 \mathrm{~km}$.

\section{Results and Discussion}

\subsection{Customer Data Analysis}

Before calculating the Link Power Budget parameters, then validate the data of internet customer installation. The subscriber data is verified and validated to find out that the existing internet registration number and internet number are installed in the customer's home well. The result of complete customer data analysis can be seen in Table 3 .
Table 3: Customer Data Analysis

\begin{tabular}{|l|c|c|c|c|}
\hline \multirow{2}{*}{ Optical Terminal Box (OTB) } & \multicolumn{3}{|c|}{ Status ONU } & \multirow{2}{*}{ Total } \\
\cline { 2 - 4 } & Good & Offline & Fallout & \\
\hline ODC-FAA & 5 & 1 & 3 & 9 \\
\hline ODC-FAB & 22 & 2 & 2 & 26 \\
\hline ODC-FB & 6 & & 3 & 9 \\
\hline ODC-FC & 4 & 1 & 2 & 7 \\
\hline ODP-FE & 4 & & 2 & 6 \\
\hline ODC-FF & 11 & & 2 & 13 \\
\hline ODP-FG & 8 & 2 & 2 & 12 \\
\hline ODC-FJ & 1 & & 1 & 2 \\
\hline ODC-FK & & & 4 & 4 \\
\hline ODC-FL & & & 2 & 2 \\
\hline ODC-FM & 25 & 2 & 11 & 38 \\
\hline ODC-FT & 11 & & & 11 \\
\hline ODC-FU & 4 & & & 4 \\
\hline ODC-FV & 3 & & & 3 \\
\hline ODC-FW & 2 & 1 & & 3 \\
\hline ODC-FX & 4 & & & 4 \\
\hline Total & 110 & 9 & 34 & 153 \\
\hline
\end{tabular}

From the results of field observations based on customer data registered at the central office, there are obstacles when taking measurements, some ODC cannot be measured (offline and fallout) so that the number of customers that can be measured only 110 users.

\subsection{Feasibility Analysis of Measurement Results}

Attenuation calculation results through equation (1), with a constant value for wavelength $1310 \mathrm{~nm}$, Standard attenuation $0.35 \mathrm{~dB}$ for fiber cable, 1:32 splitter attenuation $(17.63 \mathrm{~dB})$, connector attenuation $0.25 \mathrm{~dB} /$ item with a number of connections 5 (connection attenuation 0.1), then the total attenuation value (power budget) is presented in Fig. 3, and Table 4.

For examples of the calculation of total attenuation at the ODC-FJ optical terminal box using equation (1) as follows:

$$
\begin{aligned}
\alpha \text { tot } & =(3.2 \times 0.35)+(5 \times 0.25)+(5 \times 0.1)+(7.25+10.38) \\
& =1.12+1.25+0.5+17.63 \\
& =20.5 \mathrm{~dB}
\end{aligned}
$$

The calculation result of the Link Power Budget with the closest distance of $0.9 \mathrm{Km}$ with a total attenuation of $19.70 \mathrm{~dB}$. The farthest distance of $6.5 \mathrm{Km}$ with an attenuation value of around 21.66 $\mathrm{dB}$, the average immersion value of 110 optical terminal boxes is $20.58 \mathrm{~dB}$. Based on the standardization of ITU-T G.984.2 recommendations. For Class A: 5-20 dB, Class B: 10-25 dB, and Class C: $15-3028 \mathrm{~dB}$ [6-8], with Maximum fibre distance between S/R and $\mathrm{R} / \mathrm{S}$ points is $20 \mathrm{Km}$. So that when compared with the average total attenuation value obtained from the measured result against the recommendation standard of ITU-T G.984.x, it is still appropriate (accepted) with the benchmark. 


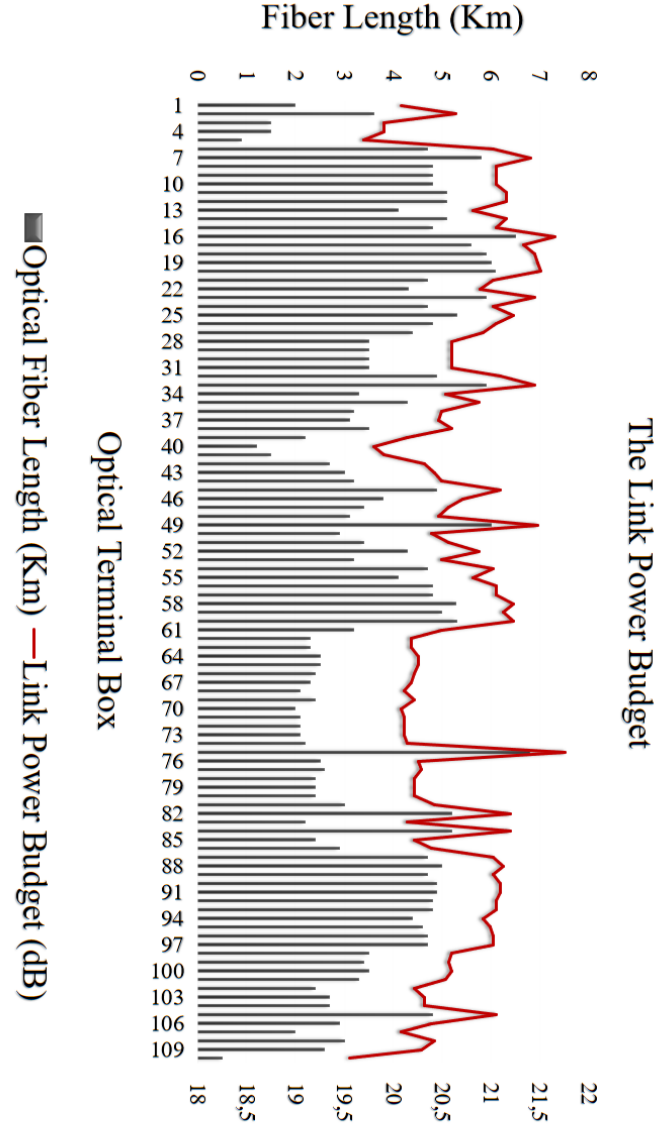

Attenuation (dB)

Fig. 3. The Link Power Budget Graph

Table 4: Summary of the Link Power Budget calculation results

\begin{tabular}{|l|c|c|c|}
\hline Optical Terminal Box & $\begin{array}{c}\text { Average Fiber } \\
\text { Length }(\mathrm{Km})\end{array}$ & $\begin{array}{c}\text { Attenuation } \\
\text { Splitter } \\
(\mathrm{dB})\end{array}$ & $\begin{array}{c}\text { Attenuation } \\
\text { Total } \\
(\mathrm{dB})\end{array}$ \\
\hline ODC-FAA & 1,900 & 17,63 & 20,05 \\
\hline ODC-FAB & 5,150 & 17,63 & 21,18 \\
\hline ODC-FB & 4,133 & 17,63 & 20,83 \\
\hline ODC-FC & 3,475 & 17,63 & 20,60 \\
\hline ODP-FE & 2,100 & 17,63 & 20,12 \\
\hline ODC-FF & 3,700 & 17,63 & 20,68 \\
\hline ODP-FG & 4,648 & 17,63 & 21,01 \\
\hline ODC-FJ & 3,200 & 17,63 & 20,50 \\
\hline ODC-FM & 2,772 & 17,63 & 20,35 \\
\hline ODC-FT & 4,745 & 17,63 & 21,04 \\
\hline ODC-FU & 3,425 & 17,63 & 20,58 \\
\hline ODC-FV & 2,600 & 17,63 & 20,29 \\
\hline ODC-FW & 3,850 & 17,63 & 20,73 \\
\hline ODC-FX & 2,025 & 17,63 & 20,09 \\
\hline \multicolumn{3}{|l|}{ Average(dB) } & 20.58 \\
\hline
\end{tabular}

Power margin, power budget margin generally includes aging of the fiber, aging of the transmitter and receiver components, additional devices, incidental twisting and bending of the fiber, additional splices, etc. The margin is needed to compensate for link degradation, which is within the range of 3 to $10 \mathrm{~dB}$ [21]. Based on the calculation of the total attenuation that is present then the value of power margin can be calculated based on equation (2). The Link power margin calculation results summarized in Table 5 and the total Link Power Budget and margin power graphs are presented in Fig. 4.
Table 5: Summary of the Power Margin calculation results

\begin{tabular}{|c|c|c|c|c|c|}
\hline $\begin{array}{c}\text { Optical } \\
\text { Terminal } \\
\text { Box }\end{array}$ & $\begin{array}{c}\mathrm{Pt} \\
(\mathrm{dBm})\end{array}$ & $\begin{array}{c}\mathrm{Pr} \\
(\mathrm{dBm})\end{array}$ & $\begin{array}{l}\text { Attenuation } \\
\text { Total (dB) }\end{array}$ & $\begin{array}{l}\text { Safety } \\
\text { Margin } \\
(\mathrm{SM})\end{array}$ & $\begin{array}{l}\text { Margin } \\
\text { Power } \\
(\mathrm{dBm})\end{array}$ \\
\hline ODC-FAA & 5 & -29 & 20,05 & 8 & 6,21 \\
\hline ODC-FAB & 5 & -29 & 21,18 & 8 & 5,07 \\
\hline ODC-FB & 5 & -29 & 20,83 & 8 & 5,42 \\
\hline ODC-FC & 5 & -29 & 20,6 & 8 & 5,65 \\
\hline ODP-FE & 5 & -29 & 20,12 & 8 & 4,72 \\
\hline ODC-FF & 5 & -29 & 20,68 & 8 & 5,58 \\
\hline ODP-FG & 5 & -29 & 21,01 & 8 & 5,24 \\
\hline ODC-FJ & 5 & -29 & 20,5 & 8 & 5,75 \\
\hline ODC-FM & 5 & -29 & 20,35 & 8 & 5,90 \\
\hline ODC-FT & 5 & -29 & 21,04 & 8 & 5,21 \\
\hline ODC-FU & 5 & -29 & 20,58 & 8 & 5,67 \\
\hline ODC-FV & 5 & -29 & 20,29 & 8 & 5,96 \\
\hline ODC-FW & 5 & -29 & 20,73 & 8 & 5,52 \\
\hline ODC-FX & 5 & -29 & 20,09 & 8 & 6,16 \\
\hline \multicolumn{5}{|c|}{ Average $(\mathrm{dBm})$} & 5,57 \\
\hline & 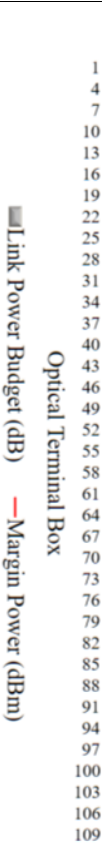 & 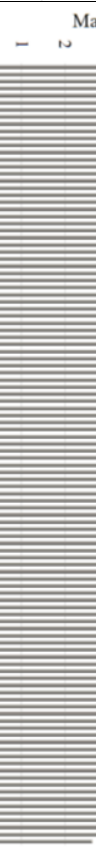 & $=\mid$ & 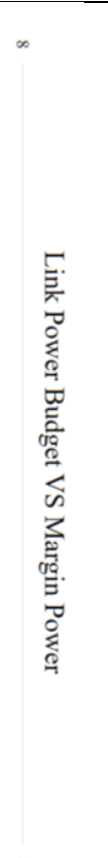 & \\
\hline
\end{tabular}

Fig. 4. The Link Power Budget and Margin Power Graph

Based on the results of measurements and calculations in Table 4 and Table 5, evaluation analysis that of the 110 customers (optical box terminals) observed in the field, the average value of the link power budget (total attenuation) is around $20.58 \mathrm{~dB}$, with the power margin average of $5.57 \mathrm{dBm}$. if compare the results of calculations with ITU-T G.984 recommendation benchmarks that require Attenuation ranges for Class A: 5-20 dB, Class B: 10-25 $\mathrm{dB}$, and Class $\mathrm{C}$ : $15-30 \mathrm{~dB}$ with Maximum Physical Distance (OLT to ONT) $20 \mathrm{Km}$, stating that it is still within the limits of the applicable standard.

In addition to analyzing the calculation of the link power budget and power margin manually based on data, the researcher also conducted monitoring to find out the records of FTTH network disturbances at STO. And the results of the monitoring that was several times in the month of the month getting reports of service disruptions did not reach the customer. These disorders are found such as the problem of bending fibre optics (micro-bending).

From interviews to field technical teams related to the implementation of FTTH networks that were not in accordance with the established standards revealed that. There are still frequent incompatibilities with standards, but are minimized. there are several factors that cause the FTTH network to be disrupted or not according to the standard, for example, the cable breaks, it could also be because the tree collapsed which made the existing device dam- 
aged There is a bend in the cable, also other factors. But when the installation takes place the FTTH network is made as safe as possible and according to the standard but not released in the future there are many network disturbances that occur. Because of that, it is necessary to periodically monitor the attenuation stabilization received by the customer whether it has been set by the standard.

\section{Conclusion}

Along with the increase and development of the use of fibre optic cables as data transmission media, often the loss of information caused by losses that occur along fibre optic cables, attenuation, and optical power problems also has a relationship with planning. To ensure and maintain the quality of services on the Fibre To The Home network with GPON technology. It is necessary to periodically monitor the attenuation stabilization received by the customer whether it has been set to standard through field measurements along the optical cable.

\section{Acknowledgement}

Thank you to the head of Information and Communication Technology Department, Universitas Mulawarman East Kalimantan, Head of Informatics Engineering Study Program which has supported this research.

\section{References}

[1] H. Alobaidan, "Current and Future FTTH Technologies." Journal of Wireless Networking and Communications 7, no. 2, pp. 35-40, 2017.

[2] P. W. Shumate, Fiber-to-the-home: 1977-2007. Journal of Lightwave Technology, vol. 26(9), pp. 1093-1103, 2008.

[3] Gigabyte Passive Optical Network (GPON) available at http://www.gpon.com/, last access July 31.2018

[4] Kumar, N.: Improved performance analysis of Gigabit passive optical networks, Optik-International Journal for Light and Electron Optics, vol. 125(7), pp. 1837-1840, 2014

[5] Israr A, Junaid M, Israr A.: Performance Analysis of Advance Optical Modulation Formats for GPON System. InFrontiers of Information Technology (FIT), 13th International Conference on, IEEE pp. 77-80, 2015.

[6] ITU-T G.984.1, Recommendation: Gigabit-capable passive optical networks (GPON): General characteristics, March 2008

[7] ITU-T G.984.2, Recommendation: GPON: Physical Media Dependent (PMD) layer specification, March 2003.

[8] ITU-T G.984.3, Recommendation G-PON: Transmission Convergence Layer Specification, January 2014.G. O. Young, "Synthetic structure of industrial plastics (Book style with paper title and editor)," in Plastics, 2nd ed. vol. 3, J. Peters, Ed. New York: McGrawHill, 1964, pp. 15-64.

[9] E. Budiman and O. Wicaksono, "Measuring quality of service for mobile internet services," 2016 2nd International Conference on Science in Information Technology (ICSITech), Balikpapan, 2016, pp. 300-305. doi: 10.1109/ICSITech.2016.7852652.

[10] E. Budiman and S. N. Alam, "User perceptions of mobile internet services performance in Borneo," 2017 Second International Conference on Informatics and Computing (ICIC), Jayapura, 2017, pp. 1-6. doi: 10.1109/IAC.2017.8280643

[11] E. Budiman, U. Haryaka, J. R. Watulingas and F. Alameka, "Performance rate for implementation of mobile learning in network," 2017 4th International Conference on Electrical Engineering, Computer Science and Informatics (EECSI), Yogyakarta, 2017, pp. 1-6. doi: 10.1109/EECSI.2017.8239187.

[12] E. Budiman, D. Moeis and R. Soekarta, "Broadband quality of service experience measuring mobile networks from consumer perceived," 2017 3rd International Conference on Science in Information Technology (ICSITech), Bandung, 2017, pp. 423-428. doi: 10.1109/ICSITech.2017.8257150.

[13] Budiman, E., Haeruddin, Hairah, U., and Alameka, F., "Mobile learning: Visualizing contents media of data structures course in mobile networks", Journal of Telecommunication, Electronic and Computer Engineering, vol. 10 (1-9), 2018, pp. 81-86.
[14] Budiman E., Hairah, U., and Saudek, A., Mobile Networks for Mobile Learning Tools, Journal of Telecommunication, Electronic and Computer Engineering, vol. 10 (1-4), 2018, pp. 47-52.

[15] Keiser, G., FTTX concepts and applications, John Wiley \& Sons, vol 91, p.196, 2006.

[16] Farmer J, Lane B, Bourg K, Wang W.: FTTx Networks: Technology Implementation and Operation, 1st edn, Morgan Kaufmann, p.51 (2016).

[17] Ubaidillah, A., and R. Alfita. "Link Power Budget and Traffict QoS Performance Analysis of Gygabit Passive Optical Network." In Journal of Physics: Conference Series, vol. 953, no. 1, p. 012129. IOP Publishing, 2018.

[18] M. El-Ghazali Hamza and K. Bashir Bugaje, "Enhancement of Gigabit Passive Optical Highspeed Network using Fiber-To-TheHome," 2018 International Conference on Computer, Control, Electrical, and Electronics Engineering (ICCCEEE), Khartoum, Sudan, 2018, pp. 1-4. doi: 10.1109/ICCCEEE.2018.8515851.

[19] M. Taruk, E. Budiman, Haviluddin and H. J. Setyadi, "Comparison of TCP variants in Long Term Evolution (LTE)," 2017 5th International Conference on Electrical, Electronics and Information Engineering (ICEEIE), Malang, 2017, pp. 131-134. doi: 10.1109/ICEEIE.2017.8328776.

[20] Hammadi, A., Talwar, R. and Singh, H., 2017. A Case Study on the Architecture, Design, Implementation and Testing of Fiber to the Home (FTTH) Green Network in Kuwait.

[21] Zhu, A, Fiber Link Power Budget: How to Make It Right? Posted on June 9, 2017, available at: http://www.fiber-optic-transceivermodule.com/fiber-link-power-budget-calculation.html. 